\title{
SECONDARY TUMOURS OF THE HEART AND PERICARDIUM
}

\author{
BY \\ ROBERT B. GOUDIE \\ From the Pathology Department of the Western Infirmary, Glasgow \\ Received July 9, 1954
}

It is perhaps not sufficiently widely realized that secondary tumours of the heart and pericardium are fairly commonly found at necropsy although they are rarely causes of clinical heart disease. It was thought worth while, therefore, to review the clinical records of cases of metastatic tumours of the heart and pericardium found at necropsy to see what evidence of their presence such tumours had produced during life.

\section{INCIDENCE AND DISTRIBUTION}

Out of 4687 consecutive post-mortem examinations performed in the Western Infirmary, Glasgow during the years 1940-1953, there were 1270 cases of malignant disease of which 126 (10 per cent) showed secondary tumours of the heart or pericardium. Since a special search for cardiac involvement was not made in these routine necropsies, it is clear that the true incidence is likely to be higher than this, and that in some instances where only single metastases have been reported, multiple involvement may have been present. The primary sites of tumours invading the heart and pericardium are shown in Table I, and Table II shows the distribution of the secondary tumours where these were found in the heart itself. Willis (1952) gives a full description of the appearance of such tumours, and their mode of spread.

\section{Clinical Features}

Tumours of the heart and pericardium are often clinically silent, and even when they produce symptoms or signs, these are usually overshadowed by the effects of the primary tumour or a metastasis to another organ. In only 20 of the 127 cases in the present series was the attention of the clinician drawn to the heart, although examination of the cardiovascular system often revealed isolated or minor abnormalities (such as poor quality of heart sounds or occasional extrasystoles) which did not arouse clinical interest. Terminal circulatory failure was common. The correct diagnosis of the cardiac pathology was never made during life in the cases reviewed.

The following summarizes the types of clinical picture that directed the physician's attention specifically to the heart in 20 cases. Congestive cardiac failure was the presenting feature in 9 , in 6 of which the existence of malignant disease was also recognized. In 7 cases there was chest pain thought to originate in the heart or pericardium, and in 4 of these myocardial infarction was suspected clinically, although in only two did the electrocardiogram support this diagnosis. Pericardial friction was noted in 6 cases. Two cases are included in the group because they presented poor quality heart sounds and electrocardiographic evidence of myocardial damage.

Arrhythmias commonly occurred in the group, sometimes being the only feature of the case to direct attention to the heart. Six patients had paroxysms of auricular fibrillation (cardiographic diagnosis was established in only one of these), and two had paroxysms of supraventricular tachycardia.

Electrocardiograms were taken in 15 of the cases and all were abnormal, showing myocardial changes, myocardial damage, the presence of an arrhythmia, or changes suggestive of coronary 
TABLE I

Primary Site of Tumours with Metastasis in Heart or Pericardium, or Both

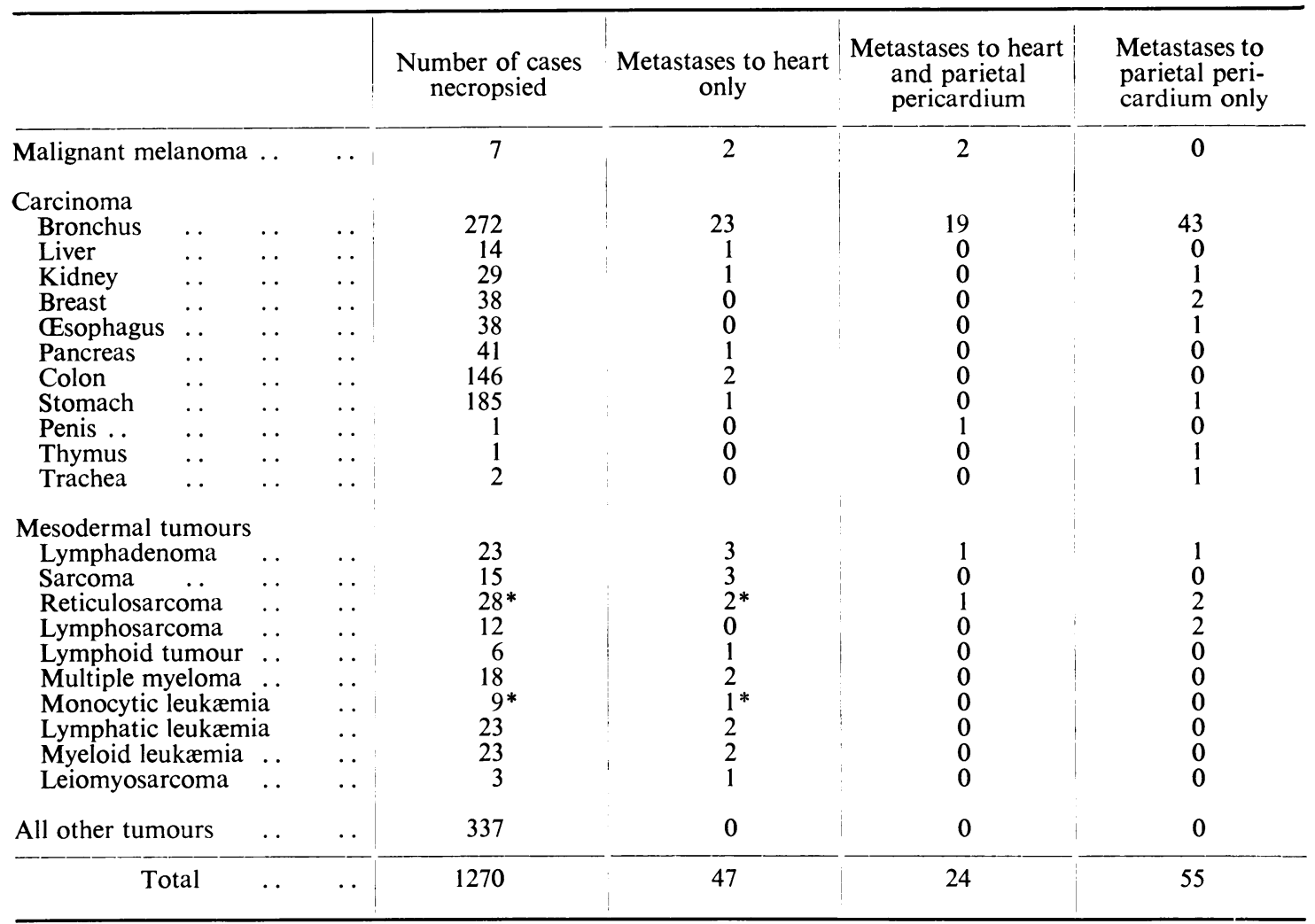

* One case with reticulosarcoma and monocytic leukæmia co-existing had tumour in the heart. It is included in the Table under both headings but appears only once in the total.

TABLE II

Pathological Findings in 71 Cases of Metastasis involving the Heart

\begin{tabular}{|c|c|c|c|}
\hline Feature considered & $\begin{array}{l}\text { Number of cases in which } \\
\text { detail is available }\end{array}$ & & Incidence \\
\hline Single or multiple metastases & 57 & $\begin{array}{l}\text { Single } \\
\text { Multiple }\end{array}$ & $\begin{array}{l}25 \\
32\end{array}$ \\
\hline Side of heart affected & 43 & $\begin{array}{l}\text { Left side only } \\
\text { Both sides } \\
\text { Right side only }\end{array}$ & $\begin{array}{l}16 \\
15 \\
12\end{array}$ \\
\hline Part of heart affected & 49 & $\begin{array}{l}\text { Atria } \\
\text { Ventricles } \\
\text { Atrial septum } \\
\text { Ventricular septum } \\
\text { Cavity of heart } \\
\text { Coronary artery }\end{array}$ & $\begin{array}{r}24 \\
32 \\
2 \\
5 \\
2 \\
1\end{array}$ \\
\hline Layer of heart affected & 63 & $\begin{array}{l}\text { Epicardium } \\
\text { Myocardium } \\
\text { Endocardium }\end{array}$ & $\begin{array}{r}39 \\
29 \\
8\end{array}$ \\
\hline
\end{tabular}


artery thrombosis. It is of interest that tracings from two patients who had tumours of the left atrium had abnormal P waves, one in leads I and II, and the other in leads II and III.

The following example shows the difficulty that may arise in the diagnosis of metastatic tumour of the heart or pericardium.

Case Report. A boilerman, aged 48, was admitted to hospital on 11/10/49, with a history of severe breathlessness of sudden onset four days previously. The breathlessness was accompanied by a tight feeling at the lower end of the sternum and at the back of the neck, profuse sweating and weakness. He went home to bed at once and the feeling of tightness passed off after 24 hours. All his symptoms improved till the day of admission when severe breathlessness and sweating recurred. Since the illness began he had lost his appetite and been troubled with gastric flatulence.

There was no relevant previous illness or familial disease, but the patient stated he had had " neuritic" pains in the left shoulder for eight months and had lost some weight during that period. For a month he had had a constant vague feeling of upper abdominal discomfort unrelated to food but associated with rumbling in his abdomen.

Examination showed the patient's temperature to be $97.0^{\circ} \mathrm{F}$., pulse 100 a minute, and respirations 28 a minute. He was restless, cyanosed, a little pale, and sweating. There was distension of the neck veins but no œdema. Slight clubbing of the fingers was present.

The pulse was irregular in rhythm and force. The radial and brachial arteries were sclerosed. The blood pressure was $120 / 80$. The apex beat was palpable in the fifth intercostal space $10 \mathrm{~cm}$. to the left of the mid-sternal line. The heart sounds were quiet and of poor quality. No murmurs or pericardial friction were heard.

The percussion note was slightly impaired and medium and fine moist sounds were heard at both lung bases, especially the right. The liver was not palpable but percussion showed it to extend $3.7 \mathrm{~cm}$. below the costal margin. No abnormality was present in the nervous system.

Examination of the blood showed $\mathrm{Hb} 12.6 \mathrm{~g}$. per $100 \mathrm{ml}$. and white cell count 10,800 per c.mm. The urine was normal.

X-ray of chest (Fig. 1) showed that the heart shadow was considerably enlarged and there was general congestion in the lungs with infiltration at the bases. On screening there was paradoxical movement of the left dome of the diaphragm. The radiologist thought there was probably a neoplasm involving the lower bronchus on the left side, together with signs of cardiac failure.

Electrocardiogram (Fig. 2) showed auricular extrasystoles and electrical alternation in leads I, CR4, and CR2. There was slurring of QRS in leads I, II, and III and inversion of T waves in leads II and III. These findings, taken with the clinical history, were interpreted as the result of a posterior coronary artery thrombosis.

The blood pressure rose to $145 / 85$ during the next two days without change in the physical signs or electrocardiogram. On 16/10/49 pericardial friction was heard, and from that date he had paroxysms of dyspnœa which gradually became more frequent: the pulse became faster, more irregular, and weaker, and after a short period of Cheyne-Stokes respirations the patient died on 18/10/49.

The diagnosis at necropsy was bronchial carcinoma extending to parietal pericardium, hæmorrhagic pericardial effusion, and acute cardiac failure. A carcinoma was found arising in a small bronchus posterior to the hilum in the lower lobe of the left lung. The tumour had spread directly for $2 \mathrm{~cm}$. to involve the left side of the parietal pericardium with a plaque $5 \mathrm{~cm}$. in diameter. The pericardial sac contained $700 \mathrm{ml}$. of heavily blood-stained fluid, and the surfaces were dulled by deposition of an irregular film of fibrin. Apart from fibrin on the epicardium the heart was normal, and the coronary arteries were healthy. Both pleural cavities were largely obliterated by fibrous adhesions. Congestion was present in lungs, liver, kidneys, and spleen.

Comment. In this case the physician was confident that the patient had died as a result of myocardial infarction in spite of a rather atypical history and evidence that there was a co-existent bronchial carcinoma.

All the cardiac manifestations of the case can be ascribed to acute cardiac tamponade five days before admission to hospital. That Claude Beck's triad of acute cardiac compression (small quiet heart, raised venous pressure, and arterial hypotension) was incomplete is explained by the patient's survival for five days giving the pericardium time to stretch and allowing the blood pressure to rise. 


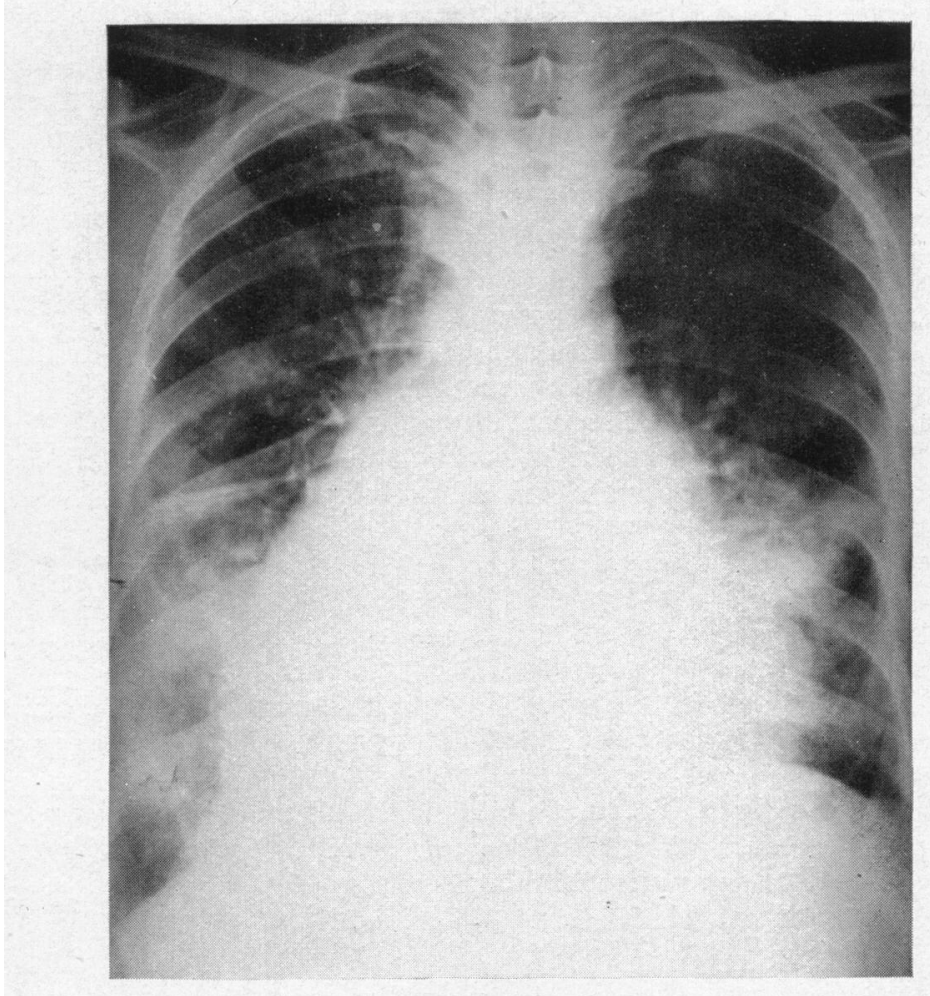

FIG. 1.-Radiogram four days after the onset of acute hæmopericardium due to bronchial carcinoma arising in the left lower lobe of lung.

Inversion of $\mathrm{T}$ waves in leads II, III, and CR7, strongly suggests posterior coronary artery thrombosis, but is also compatible with pericarditis on the fifth day of the illness (Nay and Boyer, 1946). Had the patient been seen earlier in the illness, S-T changes indicative of pericarditis and not of coronary thrombosis would probably have been present. Slurring of the QRS segment favours coronary artery disease (Barnes and Burchell, 1942). Electrical alternation as a result of malignant disease causing hæmopericardium has been described by Feldman (1938) and Reisinger et al. (1942), and has been seen by Harvey and Whitehill (1937) in tuberculous pericarditis. It is tempting to explain the cardiographic changes and the retrosternal tightness on the basis of myocardial ischæmia resulting from external compression.

\section{Discussion}

The post-mortem incidence of secondary tumours of the heart and pericardium in this series (10\%) compares with that found by Scott and Garvin (1939) who, in a series of 1082 cases of malignant disease, found the heart or parietal pericardium involved in 118 cases $(10.9 \%)$. De Loach and Haynes (1953) in 980 patients suffering from malignant disease found 137 instances $(13.6 \%)$ of involvement of the heart and pericardium. The importance of bronchial carcinoma, which frequently metastasizes to the heart or pericardium $(31 \%$ in this series of 272 cases), has often been demonstrated and is explained by the great invasiveness of that tumour, and the proximity of the primary growth and its mediastinal secondaries to the pericardium. Contrary to the usual findings, in this series carcinoma of the breast is a relatively rare tumour to metastasize to the heart and pericardium. Both sides of the heart are involved with roughly equal frequency, a finding similar to that of Scott and Garvin (1939) and Willis (1952), but at variance 

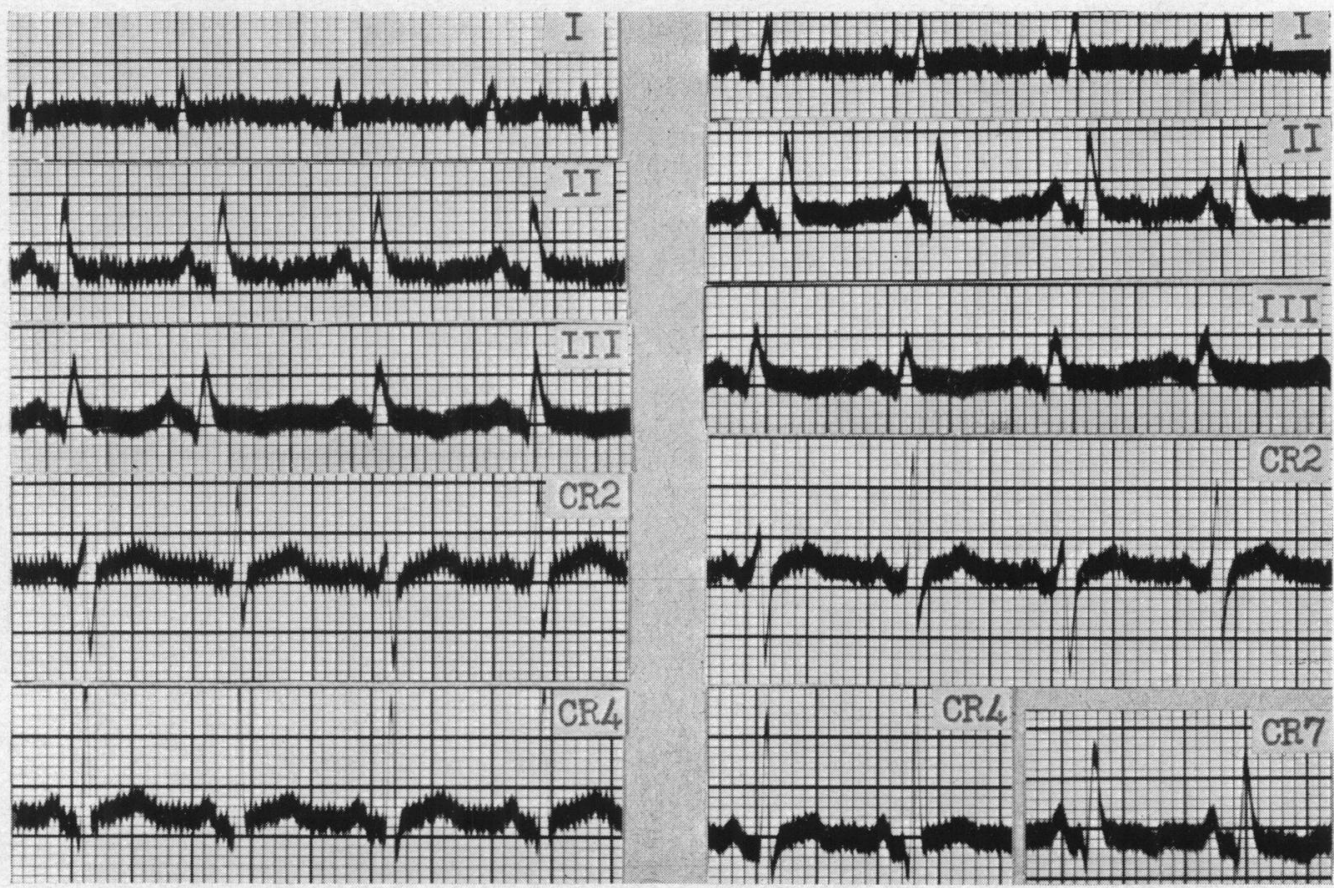

FIG. 2.-(A) Electrocardiogram taken 4 days after onset of acute hæmopericardium. Auricular extrasystoles (I and III), electrical alternation (I and CR2), and inverted T waves (II and III) are seen. CR7 was not recorded. (B) Electrocardiogram taken the day before death. There are now no auricular extrasystoles, and CR7 shows inverted T waves. Otherwise the tracings are unchanged.

with Prichard (1951) and De Loach and Haynes (1953) who found the right side more frequently involved than the left.

Detailed clinico-pathological correlation is difficult since clinical attention is so seldom directed to the heart, and the clinical picture produced is so diverse. Mahaim (1945) described some interesting cases. Often it is difficult to imagine why a metastatic tumour has not caused clinical manifestations of heart disease. The explanation may lie in the tendency of tumour tissue to compress and displace heart tissue rather than to bring about its destruction and result in gross interference with the functions of contraction and conduction. From the present study it is felt that clinical manifestations of heart disease are more often due to pericardial reaction to tumour tissue than to the direct effect of the tumour on the heart's action. Of the 20 cases in which clinical attention was drawn to the heart, 8 came from a group of 17 cases who had $100 \mathrm{ml}$. or more of blood-stained pericardial effusion, and 3 came from a group of 7 who had fibrinous or serofibrinous pericarditis, leaving only 9 cases from the group of 102 who did not have a pericardial reaction.

Prichard (1951) states that about 20 ante-mortem diagnoses of metastatic cardiac tumours have been published, the diagnosis usually being based on the development of a cardiac arrhythmia in a patient known to have widespread malignant disease. Certainly the diagnosis should always be suspected in such patients with cardiac symptoms or signs, but it can only be confirmed during life by finding malignant cells in pericardial fluid, by radiological study of the cardiac outline after induction of pneumopericardium, or at operation. As a diagnostic procedure tapping of a pericardial effusion is the only method that seems justifiable since the diagnosis can seldom be of value to the patient. Blotner and Sosman (1944) have described a case of leukæmia in which symptoms due to heart block were relieved by restoration of normal cardiac rhythm with radiotherapy. It is worth noting that heart block is a very rare manifestation of metastatic tumours of 
the heart. Electrocardiography is of little value in the diagnosis or localization of metastatic tumours of the heart or pericardium.

\section{SUMMARY}

Metastatic tumours of the heart and pericardium are found in about 10 per cent of all patients dying of malignant disease. Bronchial carcinoma is the most important primary site. Clinical manifestations of these tumours are rare, and are more often due to pericarditis than to the direct effect of the tumour itself.

An illustrative case is described in some detail.

I wish to thank Dr. J. D. Olav Kerr for helpful criticism and Dr. W. R. Snodgrass for permission to publish details of the case of hæmopericardium due to bronchial carcinoma.

\section{REFERENCES}

Barnes, A. R., and Burchell, H. B. (1942). Amer. Heart J., 23, 247.

Blotner, H., and Sosman, M. C. (1944). New Engl. J. Med., $230,793$.

De Loach, J. F., and Haynes, J. W. (1953). Arch. intern. Med., 91, 224.

Feldman, L. (1938). Amer. Heart J., 15, 100.

Harvey, A. M., and Whitehill, M. R. (1937). Medicine, 16, 45.

Mahaim, I. (1945). Les Tumeurs et les Polypes du Coeur. Masson, Paris, and Rotha, Lausanne.

Nay, R. M., and Boyer, N. H. (1946). Amer. Heart J., 32, 222.

Prichard, R. W. (1951). Arch. Path., 51, 98.

Reisinger, J. A., Pekin, T. J., and Blumenthal, B. (1942). Ann. intern. Med., 17, 995.

Scott, R. W., and Garvin, C. F. (1939). Amer. Heart J., 17, 431.

Willis, R. A. (1952). The Spread of Tumours in the Human Body. 2nd ed., Butterworth, London. 